\title{
Cervical spine alignment following surgery for adolescent idiopathic scoliosis (AIS): a pre-to-post analysis of 81 patients
}

\author{
W. Pepke ${ }^{1}$ H. Almansour ${ }^{1}$, R. Lafage², B. G. Diebo ${ }^{3}$, B. Wiedenhöfer ${ }^{4}$, F. Schwab², V. Lafage $^{2}$ and M. Akbar ${ }^{1 *}$
}

\begin{abstract}
Background: Several studies have emphasized the importance of restoring thoracic kyphosis (TK) in the setting of AIS, but very few have discussed changes in cervical spine alignment following surgery. Aim of this study was to evaluate reciprocal cervical alignment change after modification of global and regional thoracolumbar alignment with surgery in the setting of adolescent idiopathic scoliosis (AIS).

Methods: Baseline and 2-yrs follow-up radiographs of AIS patients $(n=81)$ were analysed measuring cervical parameters (upper cervical: C2-C0, McGregor Slope; lower cervical: C2-C7, C2-C7 sagittal vertical axis (SVA), C2-T3, C2-T3SVA, C2-T1Harrison (C2-T1Ha), T1 Slope (T1S)), thoracic, lumbar, pelvic and global alignment parameters. Postoperatively, patients were grouped twice; based on changes in TK and SVA. Cervical alignment was compared between groups. Pearson correlation was conducted to examine the relationship between changes in TK, SVA, and cervical alignment.
\end{abstract}

Results: Stratification by change in TK, revealed significant alteration of lower cervical alignment T1S $[p<0.001]$ ), C2-T3 [ $p=0.019], C 2-T 1 H a$ [ $p=0.043])$, but there was no reciprocal change in the upper cervical spine. Stratification by SVA revealed a significant coexisting change in the lower cervical spine (T1S [ $p<0.001]$, C2-C7SVA [ $p=0.034$, C2-T3 [ $p=0.023]$, C2-T3SVA [ $p=0.001])$. SVA change was not associated to a change in the upper cervical spine. The correlation analysis showed that with a post-operative increase in TK, the cervical spine became more lordotic. Changes in TK were significantly correlated with: $\Delta T 1 \mathrm{~S}, \Delta C 2-\mathrm{C} 7, \Delta C 2-\mathrm{T} 3$, and $\Delta C 2-T 3 S V A$. Similarly, increased cervical kyphosis was found when SVA was decreased post-operatively. Furthermore, there was a significant correlation between change of SVA and both $\triangle C 2-T 3$ and $\triangle C 2-T 3 S V A$.

Conclusions: In surgically treated AIS patients, changes in global and regional alignment of the thoracolumbar and cervical spinal segments exhibit interdependence. Thus, surgical planning with regard to sagittal deformity in AIS patients should account for the post-operative impact on cervical alignment.

Keywords: Cervical alignment, Cervical spine, Adolescent scoliosis, AIS, Deformity

\section{Background}

Spine research is in the midst of a paradigm shift focused on the physiological curvature of the cervical spine $[1,2]$. A lordotic cervical curvature is no longer considered to be the sole model of normal physiology. Recent studies support the notion that a kyphotic cervical spine can also represent normal alignment $[3,4]$.

\footnotetext{
* Correspondence: michael.akbar@med.uni-heidelberg.de

${ }^{1}$ Clinic for Orthopaedics and Trauma Surgery, Center for Orthopaedics, Trauma Surgery and Spinal Cord Injury, Heidelberg University Hospital, Schlierbacher Landstr.200a, 69118 Heidelberg, Germany

Full list of author information is available at the end of the article
}

This controversy is pervasive in studies of both the general population $[5,6]$ and scoliosis patients $[7,8]$. The lack of consensus on what constitutes normal cervical spine alignment may be explained by an incomplete understanding of how regional, global and cervical alignments interact.

Another layer of complexity is added in the setting of adolescent idiopathic scoliosis (AIS), a three-dimensional (3D) deformity that alters thoracolumbar spinal alignment with incompletely studied effects on cervical alignment [7-10]. Thus, at present it is difficult to distinguish

(C) The Author(s). 2019 Open Access This article is distributed under the terms of the Creative Commons Attribution 4.0 International License (http://creativecommons.org/licenses/by/4.0/), which permits unrestricted use, distribution, and 
physiological from pathological cervical spine alignments in AIS patients. The known global pathologic effects of scoliosis include a deforming coronal deviation of the spine with a concomitant rotation of vertebrae and a flattening of the sagittal profile [11, 12]. In recent studies of adult patients, it has been shown that sagittal alignment has a strong correlation with health-related quality of life scores [13]. Consequently, surgical planning for AIS patients has adopted a focus on sagittal alignment as an important parameter from adult spinal deformity research. In current practice, the use of rod pre-contouring (Cotrel-Dubousset technique) [14], a standard surgical procedure for AIS, provides satisfactory results in the correction of coronal deformities [15-17], but often fails to correct sagittal deformities or restore "normal" thoracic kyphosis (TK).
The relationship between cervical and thoracic sagittal alignment was initially proposed by Hilibrand et al. in 1995, showing a significant correlation between the loss of TK and the development of cervical kyphosis for the entire study group [18]. Recent studies have identified a similar correlation in AIS patients [7, 19-21]. Others have associated deterioration in cervical alignment, including loss of lordosis or development of cervical kyphosis, to the development of axial neck pain and disability [22].

We hypothesized that post-operative changes in cervical alignment correlate with changes in lumbar, thoracic, and global alignment. The purpose of this study was to investigate reciprocal changes in cervical alignment following AIS surgery and whether those changes correlate with the thoracolumbar profile.
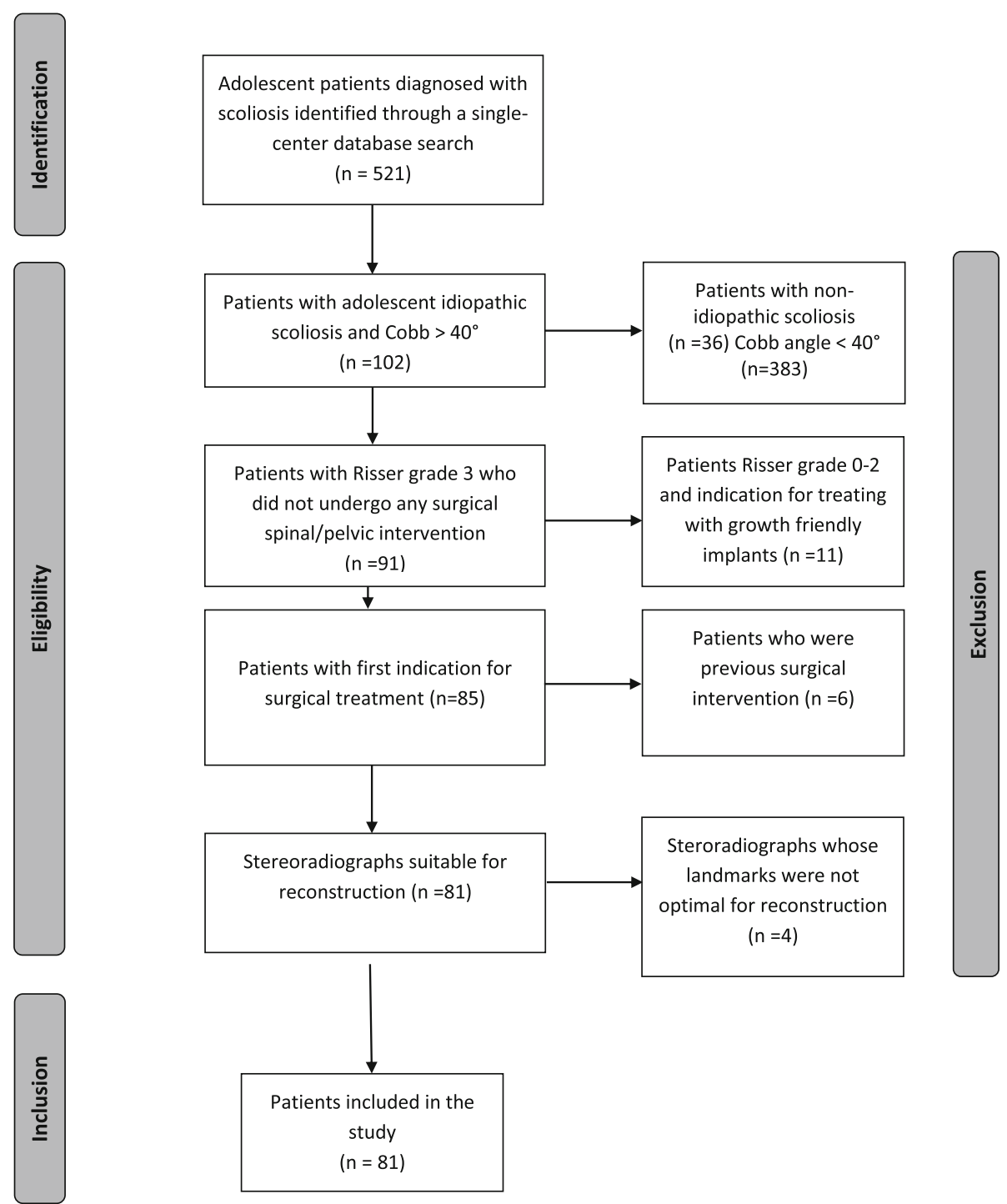

Fig. 1 Flow diagram illustrating the process of inclusion and exclusion of study cohort 


\section{Methods}

\section{Patient population}

This is a retrospective single-center study of AIS patients who were treated surgically between 2008 and 2014. Patients underwent anterior-posterior (AP) and lateral full-length $\mathrm{x}$-rays of the spine at baseline and 2-year follow up. X-rays were taken in the standing position, with patients barefoot and holding their upper extremities crossed over their chests. In order to reduce any inaccuracies due to head motion during acquisition of the radiographs, patients were instructed to look straight ahead in a relaxed position. All x-rays that did not fulfill these requirements were excluded. Further exclusion criteria were diagnoses of neuropathic or congenital scoliosis (Fig. 1).

All data was saved as a DICOM (Digital Imaging and Communications in Medicine) file and exported from PACS (Picture Archiving and Communication System) to validated software to be analysed. Assessment of spino-pelvic global alignment was performed by a single observer using SpineView ${ }^{\oplus}$ software [23].

The ethics committee of the medical faculty of Heidelberg University approved this study. Vote no. S-378/2016. Radiographs of our study cohort were conducted routinely. i.e. no additional radiographs were performed in the context of this study. These radiographs were retrospectively analysed. Hence, no informed consent of the participants was required to perform this study.

\section{Surgical technique}

Curve correction was performed in all patients with pedicle screw constructs. All surgeries were performed by two senior authors using a posterior midline incision with subperiosteal dissection. All screws were placed using the freehand technique [24] based on specific anatomical landmarks. The restoration of the coronal and sagittal curves was performed following Cotrel-Dubousset technique [14] using a cobalt chrome rod for the concave side and standard titanium rod for the convex side. All surgeries were performed under neurological monitoring using a triggered electromyogram device. All subjects remained free from any post-operative neurological impairment.

\section{Data collection and radiographic analysis}

Demographic and clinical characteristics of patients were obtained from medical records. Radiographic parameters included: spino-pelvic parameters [25] (pelvic incidence $[\mathrm{PI}]$, pelvic tilt $[\mathrm{PT}]$, sacral slope $[\mathrm{SS}]$, sagittal vertical axis [SVA], T1 spino-pelvic inclination [T1SPi], T1 pelvic
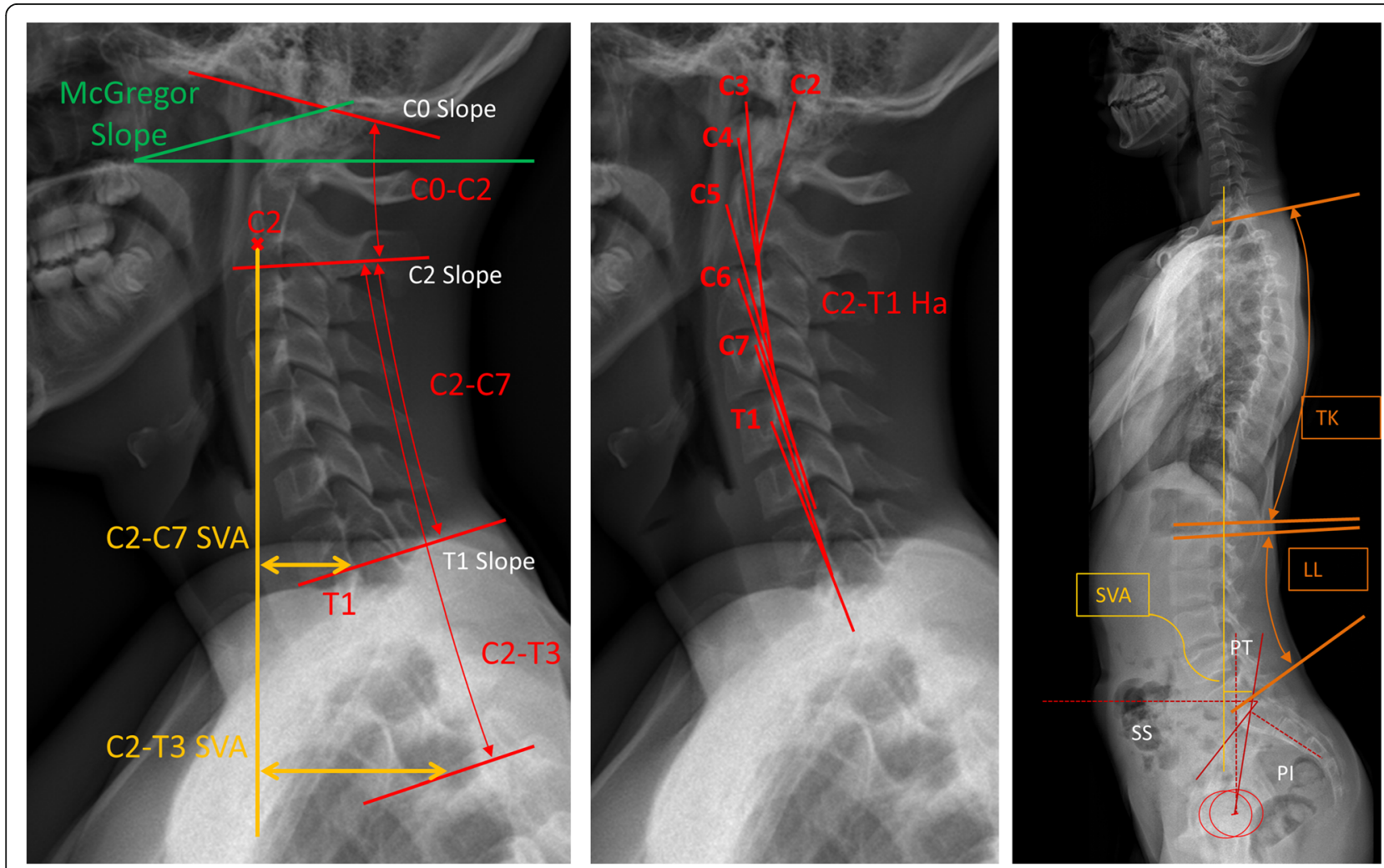

Fig. 2 Lateral radiographs illustrating cervical spine parameters. C2-T1 Ha = C2-T1 Harrison posterior tangent method. PT= pelvic tilt; PI = pelvic incidence; SS = sacral slope; LL= lumbar lordosis; TK= thoracic kyphosis; SVA = sagittal vertical axis; MGS= McGregor slope 
Table 1 Description of the measured parameters with their respective normative values and range

\begin{tabular}{|c|c|c|c|}
\hline Parameter & Description and clinical relevance & Normative values & range \\
\hline SS [41] & $\begin{array}{l}\text { The angle between the sacral endplate }(\mathrm{S} 1) \text { and the horizontal. } \\
\text { In asymptomatic subjects, SS correlates with PI }(r=0.81) \text {. }\end{array}$ & $41^{\circ} \pm 8^{\circ}$ & - \\
\hline PT [41] & $\begin{array}{l}\text { The angle between a line form the center of the femoral head axis } \\
\text { to the midpoint of the sacral plate and the vertical line. } \\
\text { PT reveals a compensatory mechanism and increases with loss } \\
\text { of LL. PT correlates with patient reported outcomes (disability). }\end{array}$ & $13^{\circ} \pm 6^{\circ}$ & -4.7 to $27^{\circ}$ \\
\hline PI [25] & $\begin{array}{l}\text { The angle between a line from the center of the femoral head axis } \\
\text { to the midpoint of the sacral plate and the perpendicular line } \\
\text { to the sacral plate. } \\
\text { PI is a morphological parameter, fixed in adults, and determines } \\
\text { spine-pelvic } \\
\text { alignment. PI=PT + SS }\end{array}$ & $51.9^{\circ} \pm 10^{\circ}$ & $35^{\circ}$ to $85^{\circ}$ \\
\hline PI-LL [42] & $\begin{array}{l}\text { the difference between PI an LL. Estimates the "lack of lordosis" } \\
\text { and correlates with disability patient reported outcomes HQRoL }\end{array}$ & $-8^{\circ} \pm 9^{\circ}$ & $-25^{\circ}$ to $15^{\circ}$ \\
\hline LL (L1-S1) [43] & The angle between the upper endplate of $L 1$ and sacral endplate. & $60.9^{\circ} \pm 12^{\circ}$ & $31^{\circ}$ to $88^{\circ}$ \\
\hline TK (T2-T12) [41] & $\begin{array}{l}\text { The angle between the caudal endplate of T12 and the cranial } \\
\text { endplate of T2. }\end{array}$ & $-40.6^{\circ} \pm 10^{\circ}$ & $0^{\circ}$ to $-69^{\circ}$ \\
\hline SVA [44] & $\begin{array}{l}\text { The horizontal offset from a plumbline dropped from C7 to the } \\
\text { postero-superior corner of S1. } \\
\text { SVA strongly correlates to clinical outcomes. }\end{array}$ & $-0.5 \pm 25 \mathrm{~mm}$ & $-60 m m$ to $+65 m m$ \\
\hline T1SPI [45] & $\begin{array}{l}\text { The angle between vertical and a line from the center of the } \\
\text { femoral head axis to the center of the T1 vertebral body. } \\
\text { T1SPI assesses the global spino-pelvic alignment and correlates } \\
\text { with clinical outcomes. }\end{array}$ & $-1.35^{\circ} \pm 2.7^{\circ}$ & $-9.16^{\circ}$ to $7.2^{\circ}$ \\
\hline TPA [46] & $\begin{array}{l}\text { The angle formed by the center of the sacral endplate, the center } \\
\text { of the femoral head axis, and the center of T1 vertebral body. } \\
\text { TPA strongly correlates with HRQOL, PT and SVA. }\end{array}$ & $7.7^{\circ} \pm 7^{\circ}$ & $-6^{\circ}$ to $23^{\circ}$ \\
\hline T1 Slope [47] & $\begin{array}{l}\text { The angle between the horizontal line and cranial endplate of T1. } \\
\text { T1 Slope defines the orientation of the cervical spine and highly } \\
\text { correlates with SVA and TK. }\end{array}$ & $26^{\circ} \pm 10^{\circ}$ & $14^{\circ}$ to $38^{\circ}$ \\
\hline $\mathrm{CL}(\mathrm{C} 2-\mathrm{C} 7)[3]$ & $\begin{array}{l}\text { The angle between the caudal endplate of } C 2 \text { and the caudal } \\
\text { endplate of } C 7 \text {. } \\
C L \text { increases with positive sagittal malalignment in order to } \\
\text { maintain horizontal gaze. }\end{array}$ & $5^{\circ} \pm 12^{\circ}$ & $-10^{\circ}$ to $22^{\circ}$ \\
\hline CSVA (C2-C7 SVA) [2] & $\begin{array}{l}\text { The horizontal offset from the plumbline dropped from C2 } \\
\text { to the postero-superior corner of C7. } \\
\text { CSVA is a descriptor of cervical sagittal deformity. }\end{array}$ & $26 \pm 11 \mathrm{~mm}$ & $12 \mathrm{~mm}$ to $40 \mathrm{~mm}$ \\
\hline C2-T3 & $\begin{array}{l}\text { The angle between the caudal endplate of C2 and the caudal } \\
\text { endplate of T3. }\end{array}$ & - & - \\
\hline C2-T3 SVA & $\begin{array}{l}\text { The horizontal offset from the plumb line dropped from C2 } \\
\text { to the postero-superior corner of T3 }\end{array}$ & - & - \\
\hline C2-T1 - H [22] & $\begin{array}{l}\text { Involves drawing lines that are parallel to the posterior surfaces } \\
\text { of all cervical vertebral bodies from C } 2 \text { to } \mathrm{T} 1 \text { and then summing } \\
\text { the segmental angles for an overall cervical } \\
\text { curvature angle. The Harrison method is a precise method } \\
\text { of quantifying cervical curvature. }\end{array}$ & about $41.8^{\circ}$ & - \\
\hline C2 Slope & $\begin{array}{l}\text { The angle between the horizontal line and cranial endplate of C2. } \\
\text { C2 Slope defines the orientation of upper cervical spine. }\end{array}$ & - & - \\
\hline Co Slope & $\begin{array}{l}\text { The angle between the horizontal and cranial ring of CO. } \\
\text { CO Slope defines the orientation of upper cervical spine. }\end{array}$ & - & - \\
\hline MGSlope [48] & $\begin{array}{l}\text { The angle between the horizontal line and a line connecting } \\
\text { the posterior aspect of the hard palate and the opisthion. }\end{array}$ & $1.8^{\circ} \pm 6.3^{\circ}$ & - \\
\hline
\end{tabular}

SS sacral slope, PT pelvic tilt, PI Pelvic incidence, LL (L1 - S1) lumbar lordosis measured from L1 to S1, PI-LL pelvic incidence minus lumbar lordosis mismatch, TK (TK 2 - TK 12) thoracic kyphosis measured from TK 2 to TK 12, SVA sagittal vertical axis, T1SPi T1 spinopelvic inclination, TPA T1 pelvic angle; cranial, COS CO Slope, C2S C2 Slope, C2-C0 angle; C2-C7 angle, C2-C7 SVA (SVA sagittal vertical axis), C2-T3angle, C2-T3 SVA (SVA sagittal vertical axis), T1 Slope, MGS McGregor Slope (line), HRQOL Health-Related Quality of Life, --- not estimated 
Table 2 Stratification based on the change on lumbar lordosis (LL), thoracic kyphosis (TK) and sagittal vertical axis (SVA)

\begin{tabular}{ccl}
\hline Stratification based on the change in $\mathrm{LL}, \mathrm{TK}$ and SVA & \\
\hline Thoracic Kyphosis (TK) & & \\
Increase: $\Delta T K<-5^{\circ}$ & Stable: $\Delta \mathrm{TK}=\left[-5^{\circ} ; 5^{\circ}\right]$ & Decrease: $\Delta \mathrm{TK}>5^{\circ}$ \\
Sagittal Vertical Axis (SVA) & & \\
Increase: $\Delta \mathrm{SVA}>25 \mathrm{~mm}$ & Stable: $\Delta \mathrm{SVA}=$ & Decrease: \\
& {$[-25 \mathrm{~mm} ; 25 \mathrm{~mm}]$} & $\Delta$ SVA $<-25 \mathrm{~mm}$
\end{tabular}

$T K$ thoracic kyphosis, SVA sagittal vertical axis, $\Delta=$ parameter change pre- to-post-operatively

angle [TPA]); regional alignment (lumbar lordosis [LL], thoracic kyphosis [TK]: T2 to T12); lower cervical (C2-C7, C2-C7 SVA, C2-T3, C2-T3 SVA, C2-T1 Harrison measurement [C2-T1-Ha] [26]) (Fig. 2); and upper cervical alignment parameters (C0 Slope, C2 Slope, C2-C0 Cobb angle, McGregor Slope [MGSlope] [27]) (Table 1). Negative values for angles denote kyphosis.

\section{Patient stratification}

Sagittal alignment was compared between baseline and 2-year follow-up. Patients were grouped based on changes in their TK and SVA into: increased TK $\left(\Delta \mathrm{TK}<-5^{\circ}\right.$; $n=40)$, stable TK $\left(\Delta \mathrm{TK}\right.$ between $-5^{\circ}$ to $\left.5^{\circ} ; n=31\right)$, and decreased TK $\left(\Delta \mathrm{TK}>5^{\circ} ; n=10\right)$; increased SVA $(\triangle \mathrm{SVA}>25 \mathrm{~mm} ; \mathrm{n}=31)$, stable/neutral SVA $(\Delta \mathrm{SVA}=-$ $25 \mathrm{~mm}$ to $25 \mathrm{~mm} ; n=23)$; and decreased SVA $(\Delta \mathrm{SVA}<$ - $25 \mathrm{~mm} ; n=27$ ) [28] (Table 2).

\section{Statistical analysis}

Cervical alignment was compared between TK and SVA groups using ANOVA. Pearson correlation analysis was utilized to investigate the relationship between changes in regional/global thoracolumbar alignment and changes in regional cervical alignment. Descriptive statistics were reported as means and standard deviations of the means. The threshold of statistical significance was set at $p<0.05$.
Statistical software package SPSS 20.00 (IBM Corp., Armonk, NY, USA) was used for statistical analysis.

\section{Results}

A total of 81 patients with a mean age of $15.47( \pm 3.5)$ years, and $74 \%$ female were included in the study. Baseline, postoperative, and $\Delta$ (amount of change) of pelvic, thoracolumbar, and cervical sagittal parameters were reported (see Table 3 and Table 4).

Stratification by change in TK (increased by $>5^{\circ}$, changed by $\leq 5^{\circ}$, decreased by $>5^{\circ}$ )

AIS patients whose TK increased post-operatively had a smaller baseline TK (TK: $-28^{\circ}$ vs. $-43^{\circ}$ vs. $-48^{\circ}, p<0.001$ ) and a kyphotic cervical spine (C2-T3: $-10^{\circ}$ vs. $-5^{\circ}$ vs. $7^{\circ}$, $p=0.053)$. Patients with increased TK post-operatively had more posterior global alignment after surgery (SVA: $4 \mathrm{~mm}$ vs. $-7 \mathrm{~mm}$ vs. $34 \mathrm{~mm}, p=0.034$; T1SPi: $-5^{\circ}$ vs. $-5^{\circ}$ vs. $\left.-1^{\circ}, p=0.004\right)$. Stratifying patients by their pre-to-post-operative TK change $(\Delta \mathrm{TK})$ revealed additional associations. Patients with an increase in TK had an increased $\Delta \mathrm{LL}$ postoperatively $\left(\Delta \mathrm{LL}: 3^{\circ}\right.$ vs. $-3.5^{\circ}$ vs. $\left.-7^{\circ}, p=0.008\right)$, an increase of $\Delta \mathrm{T} 1$ Slope $\left(\Delta \mathrm{T} 1\right.$ Slope: $6^{\circ}$ vs. $1^{\circ}$ vs. $\left.-5^{\circ}, p<0.001\right)$. The same group of patients also exhibited increased lower cervical spine lordosis postoperatively $\left(\Delta \mathrm{C} 2-\mathrm{T} 3: \mathrm{C}^{\circ}\right.$ vs. $-1^{\circ}$ vs. $-8^{\circ}, p=0.019$ ) (Fig. 3a) (see Table 5).

Stratification by change in SVA (more than $25 \mathrm{~mm}$, within, and less than - $25 \mathrm{~mm}$ )

Baseline parameters of patients who were stratified according to their SVA revealed that patients with a post-operative increase in SVA had a smaller preoperative TK $\left(-31^{\circ}\right.$ vs. $-37^{\circ}$ vs. $\left.-44^{\circ}, p=0.012\right)$ and were more posteriorly aligned (T1SPi: $-7^{\circ}$ vs. $-4^{\circ}$ vs. $\left.-1^{\circ}, p<0.001\right)$. Furthermore, they had a smaller pre-operative T1 Slope $\left(15^{\circ}\right.$ vs. $22^{\circ}$ vs. $\left.27^{\circ}, p<0.001\right)$, larger cervical kyphosis (C2-C7: $-7^{\circ}$ vs. $-2^{\circ}$ vs. $4^{\circ}, p=0.05$; C2-T3: $-11^{\circ}$ vs. $-7^{\circ}$ vs.

Table 3 Descriptive analysis of spino-pelvic and global alignment parameters in AIS patients pre- and post-operatively

\begin{tabular}{|c|c|c|c|c|c|c|c|c|c|c|c|c|}
\hline \multirow[b]{2}{*}{ Parameter } & \multicolumn{4}{|l|}{ Pre-OP } & \multicolumn{4}{|c|}{ Post-OP } & \multicolumn{4}{|c|}{ Change $=\Delta$} \\
\hline & Min & Max & Mean & SD & Min & Max & Mean & SD & Min & Max & Mean & $\mathrm{SD}$ \\
\hline SS & 6.1 & 62.2 & 40.5 & 10.5 & 12.0 & 72.6 & 40.9 & 11.2 & -12.5 & 17.9 & 0.4 & 6.8 \\
\hline PT & -6.0 & 30.5 & 12.2 & 8.1 & -17.7 & 30.5 & 11.7 & 9.0 & -16.4 & 10.9 & -0.5 & 6.5 \\
\hline $\mathrm{Pl}$ & 15.2 & 82.9 & 52.6 & 13.7 & 16.0 & 81.8 & 52.5 & 13.4 & -4.8 & 4.3 & -0.1 & 1.9 \\
\hline Pl-LL & -41.2 & 29.8 & -4.9 & 12.8 & -34.5 & 27.2 & -4.3 & 13.2 & -21.5 & 25.3 & 0.6 & 10.6 \\
\hline LL (L1-S1) & 20.0 & 91.7 & 57.5 & 12.9 & 21.7 & 87.2 & 56.8 & 13.6 & -25.9 & 22.8 & -0.7 & 10.4 \\
\hline TK (T2-T12) & -91.2 & 17.5 & -36.7 & 17.0 & -93.6 & -5.2 & -33.1 & 13.8 & -30.9 & 49.8 & -1.1 & 14.3 \\
\hline SVA & -111.6 & 143.5 & 1.2 & 46.4 & -98.6 & 168.2 & -0.6 & 45.5 & -140.4 & 172.9 & -1.8 & 49.3 \\
\hline T1SPI & -11.7 & 7.4 & -4.2 & 4.3 & -15.4 & 6.5 & -4.3 & 4.0 & -15.1 & 12.5 & -0.1 & 4.6 \\
\hline TPA & -9.3 & 28.3 & 8.0 & 7.4 & -16.9 & 27.2 & 7.4 & 8.8 & -15.5 & 14.3 & -0.6 & 6.2 \\
\hline
\end{tabular}

SS sacral slope, $P T$ pelvic tilt, $P I$ Pelvic incidence, $L L(L 1$ - S1) lumbar lordosis measured from $L 1$ to S1, PI-LL pelvic incidence minus lumbar lordosis mismatch, TK (TK 2 - TK 12) thoracic kyphosis measured from TK 2 to TK 12, SVA sagittal vertical axis, T1SPi T1 spinopelvic inclination, TPA T1 pelvic angle; cranial, MGS McGregor Slope (line), $\triangle$ parameter change pre- to post-operatively, SD standard deviation 
Table 4 Descriptive analysis of cervical alignment parameters in AIS patients pre- and post-operatively

\begin{tabular}{|c|c|c|c|c|c|c|c|c|c|c|c|c|}
\hline \multirow[b]{2}{*}{ Parameter } & \multicolumn{4}{|c|}{ Pre-OP } & \multicolumn{4}{|c|}{ Post-OP } & \multicolumn{4}{|c|}{ Change $=\Delta$} \\
\hline & Min & Max & Mean & SD & Min & Max & Mean & SD & Min & Max & Mean & $\mathrm{SD}$ \\
\hline T1Slope & 81 & -8.0 & 54.3 & 20.6 & 81 & -9.1 & 60.9 & 23.4 & 81 & -18.6 & 21.9 & 2.8 \\
\hline $\mathrm{C} 2-\mathrm{C} 7$ & 75 & -35.2 & 55.2 & -1.7 & 75 & -36.3 & 59.6 & 2.8 & 71 & -23.8 & 53.6 & 5.5 \\
\hline C2-C7 SVA & 75 & -5.3 & 71.6 & 32.0 & 75 & -5.1 & 80.1 & 34.0 & 71 & -35.6 & 39.5 & 2.4 \\
\hline $\mathrm{C} 2-\mathrm{T} 3$ & 75 & -44.0 & 73.4 & -5.3 & 75 & -42.8 & 68.9 & -4.5 & 71 & -46.4 & 42.2 & 2.0 \\
\hline C2-T3 SVA & 75 & 5.6 & 123.9 & 52.7 & 75 & -2.7 & 165.6 & 59.2 & 71 & -41.8 & 48.0 & 6.8 \\
\hline $\mathrm{C} 2-\mathrm{T} 1-\mathrm{H}$ & 72 & -39.2 & 79.0 & 7.3 & 73 & -34.7 & 78.6 & 12.4 & 66 & -39.5 & 49.0 & 6.1 \\
\hline C2Slope & 75 & -14.0 & 47.5 & 21.9 & 75 & -10.6 & 53.6 & 20.6 & 71 & -42.7 & 34.0 & -1.9 \\
\hline Coslope & 42 & -16.9 & 15.9 & -0.6 & 44 & -30.8 & 20.3 & -2.3 & 26 & -25.9 & 8.25 & -4.48 \\
\hline $\mathrm{C} 2-\mathrm{CO}$ & 40 & -6.2 & 35.4 & 22.4 & 44 & -9.4 & 38.6 & 21.3 & 26 & -20.3 & 8.63 & -2.25 \\
\hline MGSlope & 36 & -9.3 & 18.6 & 4.278 & 41 & -26.3 & 28.7 & 3.3 & 23 & -25.8 & 7.46 & -5.05 \\
\hline
\end{tabular}

COS C0 Slope, C2S C2Slope, C2-C0angle; C2-C7 angle, C2-C7 SVA (SVA sagittal vertical axis), C2-T3 angle, C2-T3 SVA (SVA sagittal vertical axis), T1 Slope, MGS McGregor Slope (line), $\triangle$ parameter change pre- to post-operatively, SD standard deviation

$\left.2^{\circ}, p=0.044\right)$ and a more posteriorly aligned cervical spine (C2-C7 SVA: $25 \mathrm{~mm}$ vs. $36 \mathrm{~mm}$ vs. $37 \mathrm{~mm}, p=0.002$; C2-T3 SVA: $41 \mathrm{~mm}$ vs. $57 \mathrm{~mm}$ vs. $62 \mathrm{~mm}, p=0.002$ ).

Post-operatively, these patients had a positive PI-LL mismatch $\left(2^{\circ}\right.$ vs. $-5^{\circ}$ vs. $\left.-11^{\circ}, p=0.001\right)$, smaller LL $\left(51^{\circ}\right.$ vs. $61^{\circ}$ vs. $\left.60^{\circ}, p=0.006\right)$, smaller TK $\left(-34^{\circ}\right.$ vs. $-42^{\circ}$ vs. $-46^{\circ}$,

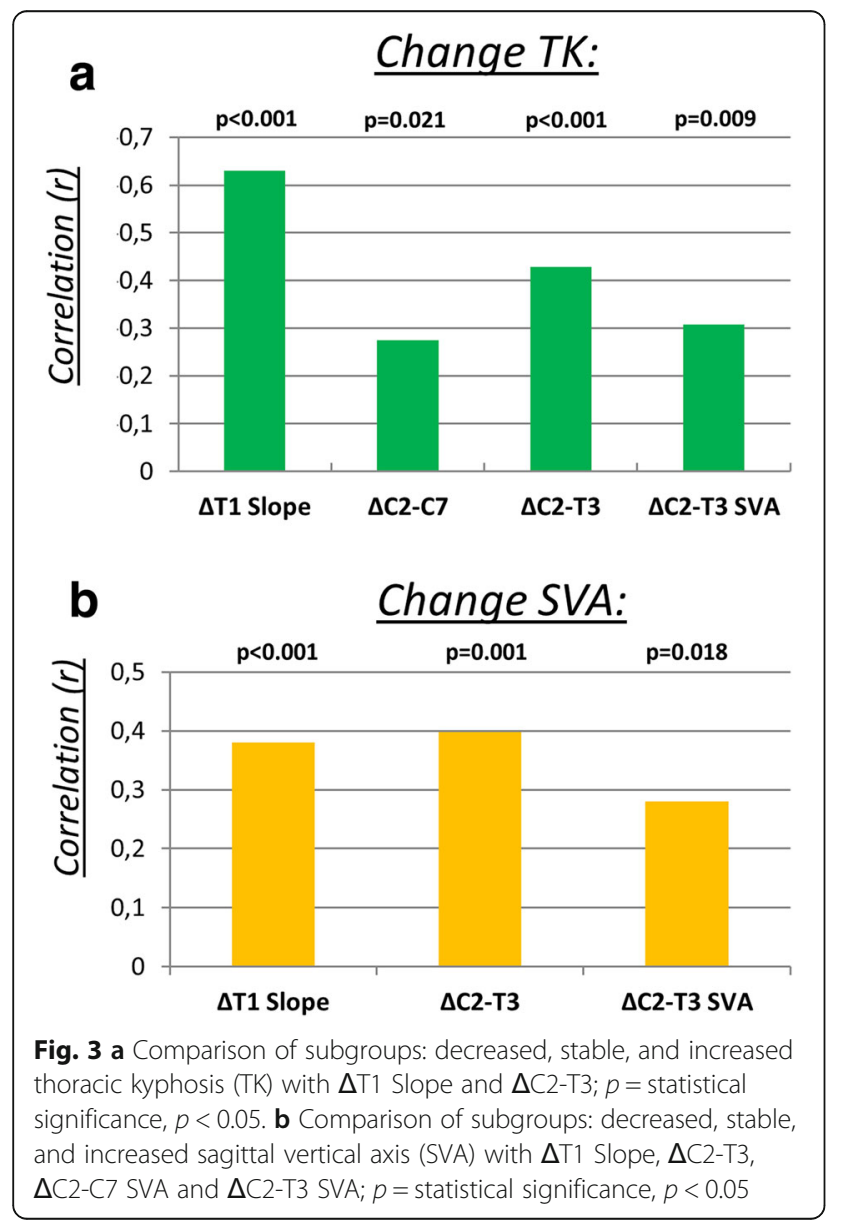

$p=0.007$ ), and were more anteriorly aligned (SVA: 20 $\mathrm{mm}$ vs. $-5 \mathrm{~mm}$ vs. $-20 \mathrm{~mm}, p=0.003$; T1SPi: $-3^{\circ}$ vs. $-5^{\circ}$ vs. $-6^{\circ}, p=0.022$; TPA: $11^{\circ}$ vs. $7^{\circ}$ vs. $\left.4^{\circ}, p=0.007\right)$.

AIS patients with increased SVA post-operatively had a larger $\Delta$ LL $\left(-5^{\circ}\right.$ vs. $1^{\circ}$ vs. $\left.3^{\circ}, p=0.008\right)$, larger $\Delta$ PI-LL $\left(5^{\circ}\right.$ vs. $-1^{\circ}$ vs. $\left.-3^{\circ}, p=0.004\right)$ and anterior change in global alignment (T1Spi: $4^{\circ}$ vs. $-1^{\circ}$ vs. $-5^{\circ}, p<0.001$; TPA: $3^{\circ}$ vs. $-1^{\circ}$ vs. $\left.-5^{\circ}, p<0.001\right)$. Furthermore, $\Delta \mathrm{T} 1$ slope, $\Delta \mathrm{C} 2-\mathrm{C} 7$ SVA, $\Delta C 2-\mathrm{T} 3$, and $\triangle \mathrm{C} 2$-T3 SVA significantly increased with increased SVA $\left(\Delta \mathrm{T} 1\right.$ Slope $6^{\circ}$ vs. $4^{\circ}$ vs. $-2^{\circ}, p<0.001$; $\Delta$ C2-C7 SVA: $8 \mathrm{~mm}$ vs. $0 \mathrm{~mm}$ vs. $-2 \mathrm{~mm}, p=0.034$; $\Delta$ C2-T3: $7^{\circ}$ vs. $3^{\circ}$ vs. $-4^{\circ}, p=0.023 ; \Delta$ C2-T3 SVA: $15 \mathrm{~mm}$ vs. $5 \mathrm{~mm}$ vs. $-1 \mathrm{~mm}, p=0.001$ ) (Fig. $3 \mathrm{~b}$ ) (see Table 6).

Regardless of patient stratification (TK or SVA), no statistical change in upper cervical parameters (C2 Slope, C0 Slope, C0-C2) was noted. Finally, the correlation analysis showed that with a post-operative increase in $\Delta \mathrm{TK}$, cervical spine curvature became more lordotic. $\Delta \mathrm{TK}$ significantly correlated with $\Delta \mathrm{T} 1$ Slope $(r=0.630 ; p<0.001), \Delta \mathrm{C} 2-\mathrm{C} 7$ $(r=0.274 ; \quad p=0.021), \quad \Delta \mathrm{C} 2-\mathrm{T} 3 \quad(r=0.428 ; \quad p<0.001)$, $\Delta$ C2-T3 SVA $(r=0.308 ; p=0.009)$ (Fig. 4a). Similarly, cervicothoracic spine curvature became more lordotic when $\triangle$ SVA increased post-operatively. There was a significant correlation between $\triangle$ SVA and $\Delta$ C2-T3 $(r=0.398$; $p=0.001)$ and $\Delta$ C2-T3 SVA $(r=0.280 ; p=0.018)$ (Fig. 4b).

\section{Discussion}

A long-held belief in the field of cervical spine research was that a kyphotic cervical spine was a source of pathology $[29,30]$. Lordosis was considered the only normal alignment [1]. The association of cervical kyphosis with a higher likelihood of concomitant diseases like cervical myelopathy or accompanying symptoms such as neck pain may have been a major contributor to the vilification of kyphotic alignment [29]. 


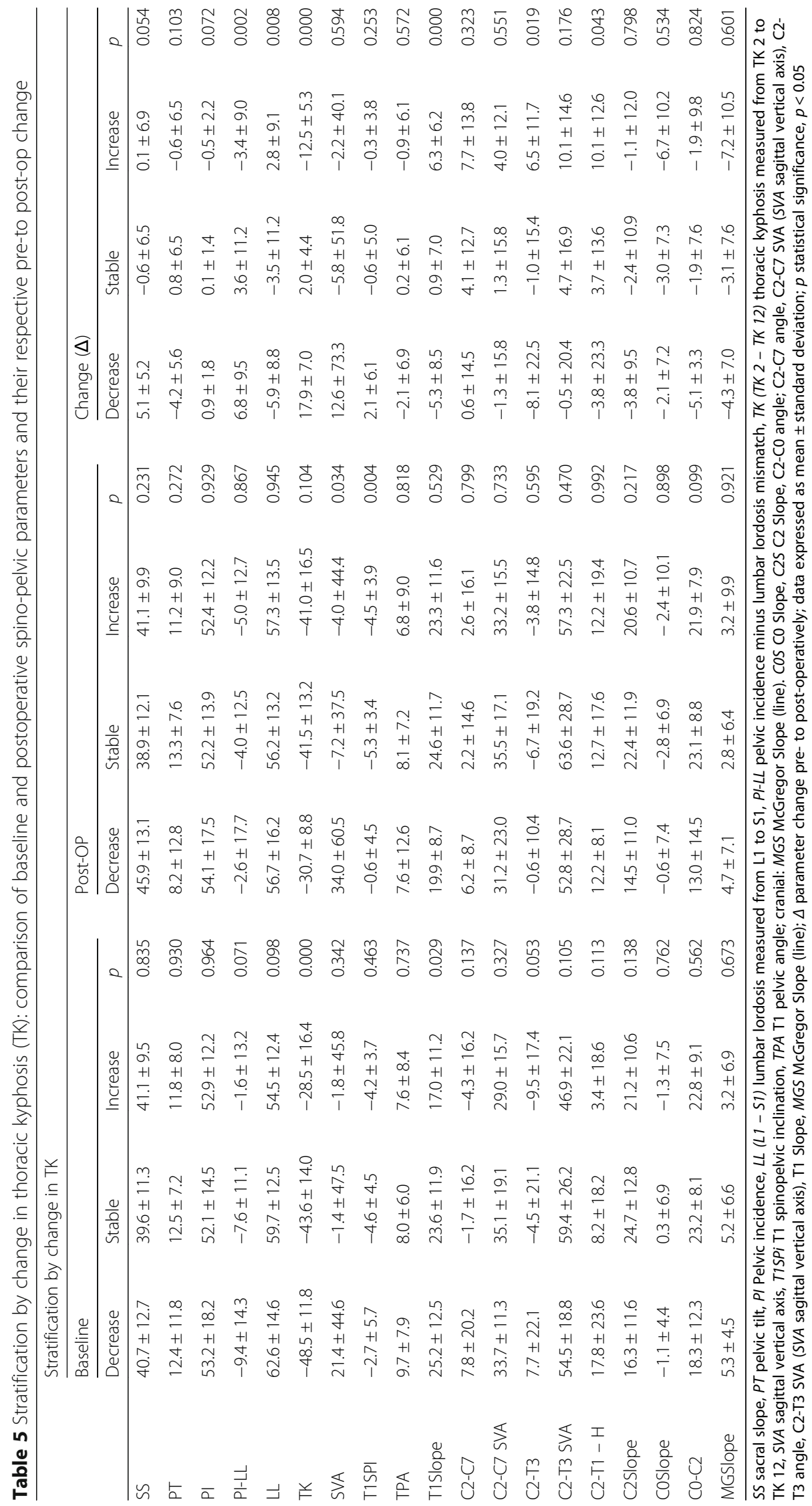




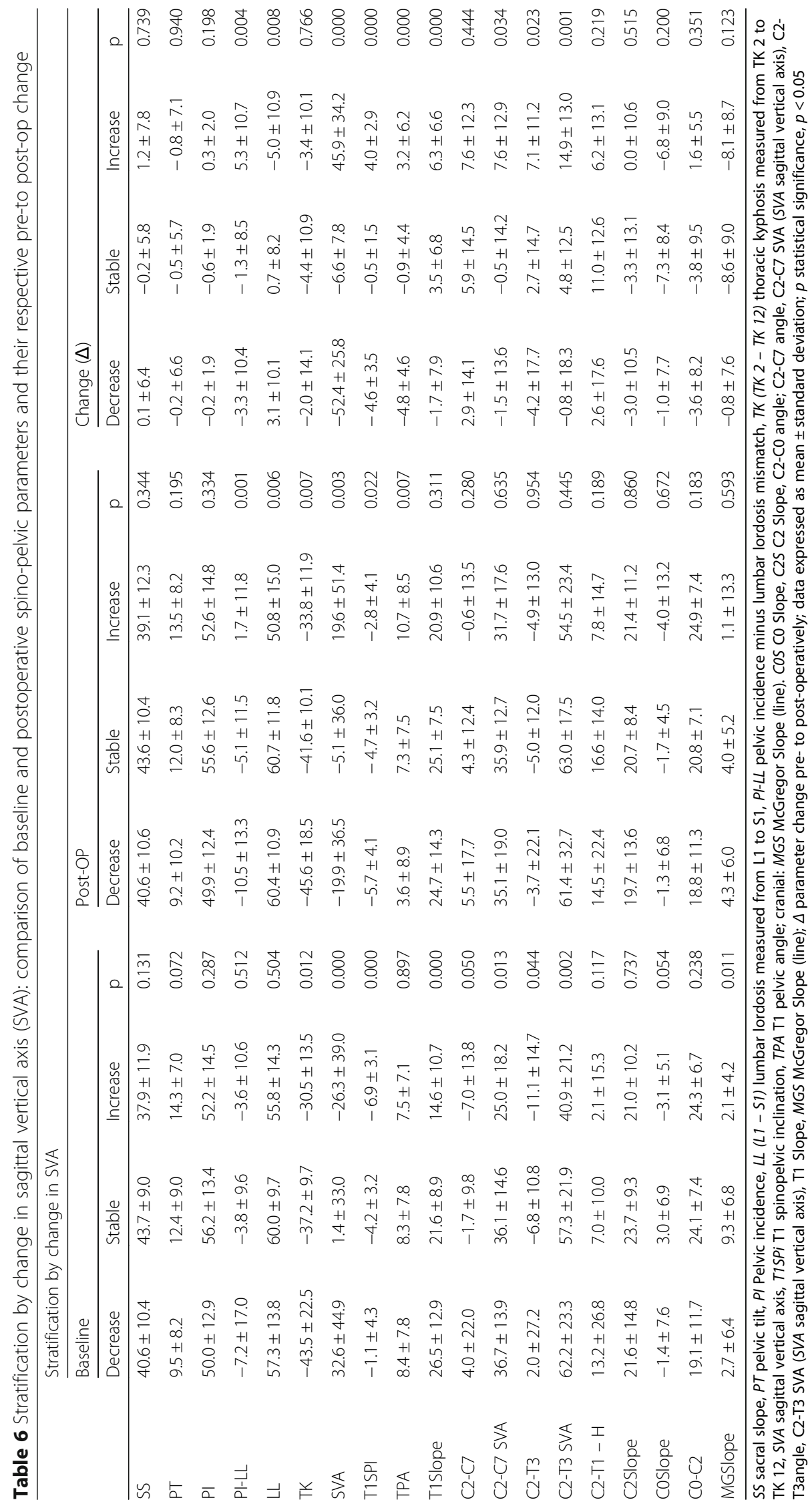




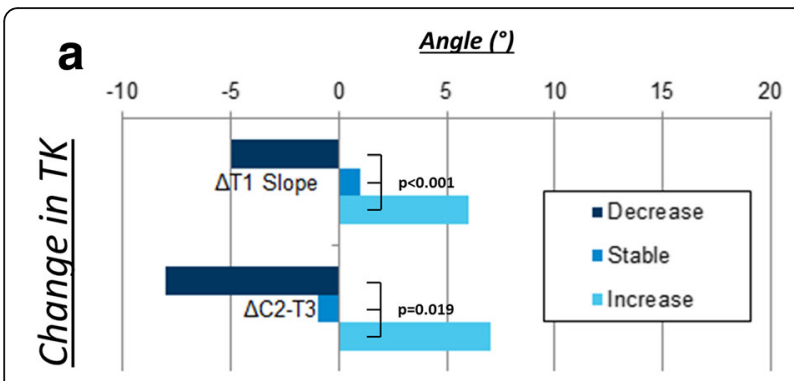

b

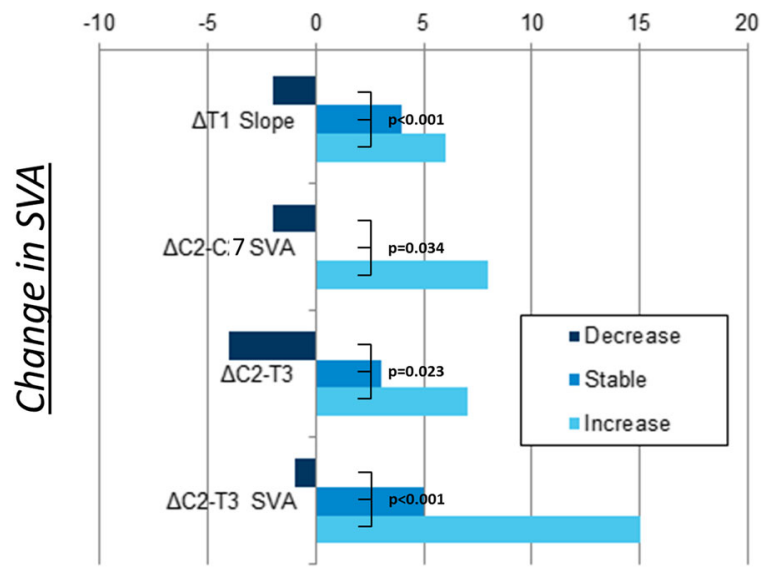

Fig. 4 a Diagram with correlation analysis of subgroup: pre-to postoperative change in thoracic kyphosis (TK) with $\Delta \mathrm{T} 1$ Slope, $\Delta C 2-C 7$, $\Delta C 2-T 3, \Delta C 2-T 3$ SVA; $p=$ statistical significance, $p<0.05$. b Diagram with correlation analysis of subgroup: pre-to post-operative change in sagittal vertical axis (SVA) with $\Delta \mathrm{T} 1$ Slope, $\Delta$ C2-T3, $\Delta$ C2-T3 SVA; $p$ $=$ statistical significance, $p<0.05$

Le Huec et al. observed that almost $30 \%$ of their asymptomatic young volunteers had a kyphotic cervical alignment [3].This finding, the presence of cervical kyphosis in young patients with no signs of pathology and no complaints, has begun to trigger a paradigm shift in conceptualizing the physiologic alignment of the cervical spine $[2,5,22]$. This has motivated many investigators to dig deeper into the complex realm of cervical alignment.

Cervical alignment is not an independent entity and should be viewed through a wider lens; global and regional alignments play hidden roles and are key players in determining cervical curvature $[9,18]$. In the context of AIS, complex 3D deformation of normal regional alignment (TK) can change cervical alignment [19-21, 31]. Understanding the intricate relationship between sagittal alignment and the cervical spine is essential for predicting its effects on cervical curvature.

In conservatively treated AIS patients, it has already been shown that the aforementioned relationship exists [32]. In this study, we hypothesized that operative treatment of AIS patients with rod-screw contouring would influence cervical alignment by altering the sagittal profile.
Our data shows that patients with pre-operative kyphosis in the lower cervical spine had a low TK and low T1 slope, which is in line with former studies that revealed T1 Slope to have an influence on cervical curvature [19-21, 31, 33, 34]. Specifically, when T1 slope decreases, the cervical spine becomes more kyphotic. In accordance with increases in T1 slope, their lower cervical spines (cervicothoracic: C2-T3) became more lordotic after surgery. The spine of AIS patients is flexible and therefore malleable through corrective surgery. When thoracic kyphosis is accentuated, the lumbar spine compensates with increasing lordosis to maintain spinal balance and position within the cone of economy [35]. Increased TK results in increased T1 Slope [33], and an increased T1 Slope has a direct effect on cervical curvature resulting in more cervical lordosis [33] as a form of compensation. In other words, the increase in lower cervical lordosis (C2-C7, C2-T3) that we observed was a compensatory mechanism to position the head near the center of gravity (C2-C7, C2-T3).

Patient stratification based on post-operative SVA unveiled important observations in terms of preoperative global, regional and cervical parameters. It also revealed how $\triangle$ SVA correlated with the aforementioned parameters. We noted that patients who exhibited an increase in SVA after surgery had a lower preoperative SVA, TK, and $\mathrm{T} 1$ Slope and were more posteriorly aligned (T1SPi) when compared to the subgroup of patients who had a decreased post-op SVA or a stable SVA. They also had a kyphotic lower cervical spine before surgery. This cervical kyphosis could also be explained by compensation attempt to position the head near the center of gravity [36]. Notably, in this subgroup of patients, TK significantly decreased without affecting T1 Slope or cervical curvature, which could be explained by the increased anterior alignment (SVA) post-operatively.

When we studied the effect of pre- to post-operative change $(\Delta)$, we noted that in the subgroup with postoperative increases in SVA, there was also a significant increase of $\Delta \mathrm{T} 1$ Slope, $\Delta \mathrm{C} 2-\mathrm{C} 7 \mathrm{SVA}$, and $\Delta \mathrm{C} 2-\mathrm{T} 3$ SVA. Thus, post-operative anterior shift in global alignment is associated with a post-operative anterior change in cervical and cervicothoracic alignment. Interestingly, $\Delta \mathrm{C} 2-\mathrm{C} 7 \mathrm{did}$ not significantly change; on the other hand, $\triangle \mathrm{C} 2-\mathrm{T} 3$ revealed a significant increase, denoting more lordosis of the cervicothoracic junction. This implies that changing SVA after surgery affects cervical sagittal alignment and changes the cervicothoracic junction with no significant effect on local cervical curvature (C2-C7). These findings are in line with findings from Diebo et al. In their adult population, the highest cSVA was observed in the subgroup whose SVA was $>50 \mathrm{~mm}$ [37].

TK and SVA correlated with lower cervical spine parameters. Specifically, we found that TK correlates with 
LL, T1 Slope, C2-C7, C2-T3, and C2-T3 SVA. Furthermore, SVA correlates with LL, C2-T3, and C2-T3 SVA. This affirms a few concepts: first, there is interdependence between regional spine parameters (TK), global alignment (SVA), and lower cervical curvature. Second, in AIS patients treated with fusion surgery, there is a range of motion reserve in unfused segments that can be recruited for compensation. Yang et al. previously discussed how unfused segments might play an important compensatory role in maintaining sagittal balance [35]. Finally, we took a step back from the lower region of the cervical spine and examined upper cervical spine parameters. No significant difference was found in terms of pre- to postoperative analysis of the influence of global and regional alignment on upper cervical alignment in AIS patients. We suggest two possible explanations. First, the lower cervical spine alone is able to compensate over five segments of motion to position the head sufficiently close to the center of gravity, making it unnecessary to recruit the upper cervical spine. Second, the upper cervical spine may have been recruited to achieve normal horizontal gaze.

In the past few years, the interdependence between TK, T1Slope, and SVA and their impact on the cervical spine in the context of degenerative disease has been proven [38]. In our study, we have shown in detail that this relationship also exists in AIS patients.

Incidence of prolonged neck pain after spinal surgery has been well described in previous studies, in which it was evident from the lower scores of patient-reported health-related quality of life (HRQOL) parameters [13, 39]. This makes it important to undertake further investigations to develop an understanding of the pathomechanism of this post-operative cervical pain, with the goal of devising therapeutic or preventative strategies.

Comprehensive preoperative planning may be a potential point of intervention. Whether prevention of post-operative cervical kyphosis by thoracic or thoraco-lumbar fusion in AIS patients leads to better clinical outcomes or does not merits a prospective investigation. Furthermore, it is already known that the presence of cervical kyphosis during a degenerative process can lead to intervertebral disc degeneration, spondylotic myelopathy, and elongation of the spinal cord [40]. None of our patients exhibited neck pain post-operatively at time of conduction of this study. However, due to the retrospective nature of our study, we could not follow up with our patients to investigate whether they developed neck pain. This constitutes one of the limitations of our study. Hence, prospective investigations are needed to assess whether post-operative cervical kyphosis in AIS patient would represent the beginning of a pathological process that would end in cervical pain.

A further limitation of our study is a potential selection bias which would jeopardize the external validity of our results as no randomization was utilized while choosing the full-spine radiographs. Furthermore, we concede that we could not stratify our study population based on Lenke classification due to resulting very small subgroups. Thus, we considered the pre- to post-operative TK and SVA to be more appropriate for our study cohort. These limitations notwithstanding, our retrospective pre- to post- analysis revealed important correlations and enabled us to disentangle complex relationships between different parts of the spine both before and after surgery.

\section{Conclusion}

Cervical curvature is influenced by post-operative changes in TK, T1 Slope, and SVA. Interestingly, all variations of the cervical parameters pre- to post-operatively were restricted to the lower cervical spine with no effect on the upper cervical spine, regardless of how patients were stratified. Due to the post-operative impact of AIS surgery on cervical alignment, we suggest that lower cervical alignment should be considered in preoperative planning.

\section{Abbreviations \\ COS: CO Slope; C2-C7 SVA: (SVA = sagittal vertical axis); C2S: C2 Slope; C2-T3 SVA: (SVA = sagittal vertical axis); DICOM: Digital Imaging and \\ Communications in Medicine; HRQOL: health-related quality of life; LL (L1 - \\ S1): lumbar lordosis measured from L1 to S1; MGS: McGregor Slope (line); \\ PACS: Picture archiving and communication system; PI: Pelvic incidence; PI- \\ LL: pelvic incidence minus lumbar lordosis mismatch; PT: pelvic tilt; SS: sacral \\ slope; SVA: sagittal vertical axis; T1SPi: T1 spinopelvic inclination; TK (TK 2 - \\ TK 12): thoracic kyphosis measured from TK 2 to TK 12; TPA: T1 pelvic angle}

\section{Acknowledgments}

Not applicable.

\section{Funding}

No funding was received in support of this work

Relevant financial activities outside the submitted work: consultancy, grants, royalties, stocks, patents.

Availability of data and materials

The datasets used and/or analysed during the current study are available from the corresponding author on reasonable request.

\section{Authors' contributions}

All authors made substantial contributions to this article. MA, VL, BD, BW, FS, WP contributed to the conception and design of the study. Data collection was performed by WP. Data analyses were performed by MA, RL, HA. All authors contributed to the interpretation of the results, and revision and correction of the report, which was drafted by WP and HA. All named authors read, revised and approved the final manuscript.

\section{Ethics approval and consent to participate}

The ethics committee of the medical faculty of Heidelberg University approved this study.

Vote no. S-378/2016

Radiographs of our study cohort were conducted routinely. i.e. no additional radiographs were performed in the context of this study. These radiographs were retrospectively analysed. Hence, no informed consent was required to perform this study.

Consent for publication

Not applicable. 


\section{Competing interests}

The authors declare that they have no competing interests.

\section{Publisher's Note}

Springer Nature remains neutral with regard to jurisdictional claims in published maps and institutional affiliations.

\section{Author details}

${ }^{1}$ Clinic for Orthopaedics and Trauma Surgery, Center for Orthopaedics, Trauma Surgery and Spinal Cord Injury, Heidelberg University Hospital, Schlierbacher Landstr.200a, 69118 Heidelberg, Germany. ${ }^{2}$ Hospital for Special Surgery, New York, NY, USA. ${ }^{3}$ Department of Orthopaedic Surgery, State University of New York, Downstate Medical Center, Brooklyn, NY, USA. ${ }^{4}$ Spine Surgery, ATOS Clinic Heidelberg, Bismarckstr. 9-15, 69115 Heidelberg, Germany.

Received: 30 January 2018 Accepted: 4 January 2019

Published online: 15 January 2019

\section{References}

1. Borden AG, Rechtman AM, Gershon-Cohen J. The normal cervical lordosis. Radiology. 1960;74:806-9.

2. Hardacker JW, Shuford RF, Capicotto PN, Pryor PW. Radiographic standing cervical segmental alignment in adult volunteers without neck symptoms. Spine. 1997;22:1472-80 discussion 1480.

3. Le Huec JC, Demezon H, Aunoble S. Sagittal parameters of global cervical balance using EOS imaging: normative values from a prospective cohort of asymptomatic volunteers. Eur Spine J. 2015;24:63-71.

4. Hey HW, Lau ET, Wong CG, Tan KA, Liu GK, Wong HK. Cervical Alignment Variations in Different Postures and Predictors of Normal Cervical Kyphosis A New Understanding. Spine. 2017:42(21):1614-21.

5. Yukawa Y, Kato F, Suda K, Yamagata M, Ueta T, Yoshida M. Normative data for parameters of sagittal spinal alignment in healthy subjects: an analysis of gender specific differences and changes with aging in 626 asymptomatic individuals. Eur Spine J. 2018;27(2):426-32.

6. Iyer S, Lenke LG, Nemani VM, Fu M, Shifflett GD, Albert TJ, Sides BA, Metz LN, Cunningham ME, Kim HJ. Variations in Occipitocervical and cervicothoracic alignment parameters based on age: a prospective study of asymptomatic volunteers using full-body radiographs. Spine. 2016;41:1837-44.

7. Hiyama A, Sakai D, Watanabe M, Katoh H, Sato M, Mochida J. Sagittal alignment of the cervical spine in adolescent idiopathic scoliosis: a comparative study of 42 adolescents with idiopathic scoliosis and 24 normal adolescents. Eur Spine J. 2016;25:3226-33.

8. Norheim EP, Carreon LY, Sucato DJ, Lenke LG, Glassman SD. Cervical spine compensation in adolescent idiopathic scoliosis. Spine Deformity. 2015;3:327-31.

9. Aykac B, Ayhan S, Yuksel S, Guler UO, Pellise F, Alanay A, Perez-Grueso FJ, Acaroglu E. Sagittal alignment of cervical spine in adult idiopathic scoliosis. Eur Spine J. 2015;24:1175-82.

10. Ito K, Imagama S, Ito Z, Ando K, Kobayashi K, Hida T, Tsushima M, Ishikawa Y, Matsumoto A, Nishida Y, Ishiguro N. Analysis of cervical kyphosis and spinal balance in young idiopathic scoliosis patients classified by the apex of thoracic kyphosis. Eur Spine J. 2016.

11. Pizones J, Nunez-Medina A, Sanchez-Mariscal F, Zuniga L, Izquierdo E. Thoracic sagittal plane variations between patients with thoracic adolescent idiopathic scoliosis and healthy adolescents. Eur Spine J. 2016;25:3095-103.

12. Clement JL, Geoffray A, Yagoubi F, Chau E, Solla F, Oborocianu I, Rampal $\vee$. Relationship between thoracic hypokyphosis, lumbar lordosis and sagittal pelvic parameters in adolescent idiopathic scoliosis. Eur Spine J. 2013;22:2414-20.

13. Jalai CM, Passias PG, Lafage V, Smith JS, Lafage R, Poorman GW, Diebo B, Liabaud B, Neuman BJ, Scheer JK, et al. A comparative analysis of the prevalence and characteristics of cervical malalignment in adults presenting with thoracolumbar spine deformity based on variations in treatment approach over 2 years. Eur Spine J. 2016;25:2423-32.

14. Dubousset J, Cotrel Y. Application technique of Cotrel-Dubousset instrumentation for scoliosis deformities. Clin Orthop Relat Res. 1991:103-10.

15. Suk SI, Lee SM, Chung ER, Kim JH, Kim SS. Selective thoracic fusion with segmental pedicle screw fixation in the treatment of thoracic idiopathic scoliosis: more than 5-year follow-up. Spine. 2005;30:1602-9.
16. Liljenqvist U, Lepsien U, Hackenberg L, Niemeyer T, Halm H. Comparative analysis of pedicle screw and hook instrumentation in posterior correction and fusion of idiopathic thoracic scoliosis. Eur Spine J. 2002;11:336-43.

17. Lehman RA Jr, Lenke LG, Keeler KA, Kim YJ, Buchowski JM, Cheh G, Kuhns $\mathrm{CA}$, Bridwell $\mathrm{KH}$. Operative treatment of adolescent idiopathic scoliosis with posterior pedicle screw-only constructs: minimum three-year follow-up of one hundred fourteen cases. Spine. 2008;33:1598-604.

18. Hilibrand AS, Tannenbaum DA, Graziano GP, Loder RT, Hensinger RN The sagittal alignment of the cervical spine in adolescent idiopathic scoliosis. J Pediatr Orthop. 1995;15:627-32.

19. Yanik HS, Ketenci IE, Erdem S. Cervical sagittal alignment in extensive fusions for Lenke 3C and 6C scoliosis: the effect of upper instrumented vertebra. Spine. 2016.

20. Pesenti S, Blondel B, Peltier E, Choufani E, Bollini G, Jouve JL. Interest of T1 parameters for sagittal alignment evaluation of adolescent idiopathic scoliosis patients. Eur Spine J. 2016;25:424-9.

21. Roussouly P, Labelle H, Rouissi J, Bodin A. Pre- and post-operative sagittal balance in idiopathic scoliosis: a comparison over the ages of two cohorts of 132 adolescents and 52 adults. Eur Spine J. 2013;22(Suppl 2):S203-15.

22. Scheer JK, Tang JA, Smith JS, Acosta FL Jr, Protopsaltis TS, Blondel B, Bess S, Shaffrey Cl, Deviren V, Lafage V, et al. Cervical spine alignment, sagittal deformity, and clinical implications: a review. J Neurosurg Spine. 2013;19:141-59.

23. Champain S, Benchikh K, Nogier A, Mazel C, Guise JD, Skalli W. Validation of new clinical quantitative analysis software applicable in spine orthopaedic studies. Eur Spine J. 2006;15:982-91.

24. Puvanesarajah V, Liauw JA, Lo SF, Lina IA, Witham TF. Techniques and accuracy of thoracolumbar pedicle screw placement. World J orthop. 2014;5:112-23.

25. Duval-Beaupere G, Schmidt C, Cosson P. A Barycentremetric study of the sagittal shape of spine and pelvis: the conditions required for an economic standing position. Ann Biomed Eng. 1992;20:451-62.

26. Harrison DE, Harrison DD, Cailliet R, Troyanovich SJ, Janik TJ, Holland B. Cobb method or Harrison posterior tangent method: which to choose for lateral cervical radiographic analysis. Spine. 2000;25:2072-8.

27. Mc GM. The significance of certain measurements of the skull in the diagnosis of basilar impression. Br J Radiol. 1948;21:171-81.

28. Lafage V, Schwab F, Skalli W, Hawkinson N, Gagey PM, Ondra S, Farcy JP. Standing balance and sagittal plane spinal deformity: analysis of spinopelvic and gravity line parameters. Spine (Phila Pa 1976). 2008:33:1572-8.

29. Kawakami M, Tamaki T, Yoshida M, Hayashi N, Ando M, Yamada H. Axial symptoms and cervical alignments after cervical anterior spinal fusion for patients with cervical myelopathy. J Spinal Disord. 1999;12:50-6.

30. Katsuura A, Hukuda S, Saruhashi Y, Mori K. Kyphotic malalignment after anterior cervical fusion is one of the factors promoting the degenerative process in adjacent intervertebral levels. Eur Spine J. 2001;10:320-4.

31. Ilharreborde B, Vidal C, Skalli W, Mazda K. Sagittal alignment of the cervical spine in adolescent idiopathic scoliosis treated by posteromedial translation. Eur Spine J. 2013:22:330-7.

32. Yu M, Silvestre C, Mouton T, Rachkidi R, Zeng L, Roussouly P. Analysis of the cervical spine sagittal alignment in young idiopathic scoliosis: a morphological classification of 120 cases. Eur Spine J. 2013;22:2372-81.

33. Wang F, Zhou XY, Xu XM, Yang YL, Zhu XD, Bai YS, Wei XZ, Li M. Cervical sagittal alignment limited adjustment after selective posterior thoracolumbar/lumbar curve correction in patients with Lenke type $5 \mathrm{C}$ adolescent idiopathic scoliosis. Spine. 2016.

34. Lee SH, Son ES, Seo EM, Suk KS, Kim KT. Factors determining cervical spine sagittal balance in asymptomatic adults: correlation with spinopelvic balance and thoracic inlet alignment. Spine J. 2015:15:705-12.

35. Yang M, Yang C, Chen Z, Wei X, Chen Y, Zhao J, Shao J, Zhu X, Li M. Lumbar lordosis minus thoracic kyphosis: remain constant in adolescent idiopathic scoliosis patients before and after correction surgery. Spine. 2016;41:E359-63.

36. Hasegawa K, Okamoto M, Hatsushikano S, Shimoda H, Ono M, Homma T, Watanabe K. Standing sagittal alignment of the whole axial skeleton with reference to the gravity line in humans. J Anat. 2017;230:619-30.

37. Diebo BG, Challier V, Henry JK, Oren JH, Spiegel MA, Vira S, Tanzi EM, Liabaud B, Lafage R, Protopsaltis TS, et al. Predicting cervical alignment required to maintain horizontal gaze based on global spinal alignment. Spine. 2016:41:1795-800.

38. Obeid I, Boniello A, Boissiere L, Bourghli A, Pointillart V, Gille O, Lafage V, Vital JM. Cervical spine alignment following lumbar pedicle subtraction osteotomy for sagittal imbalance. Eur Spine J. 2015;24:1191-8. 
39. Youn MS, Shin JK, Goh TS, Kang SS, Jeon WK, Lee JS. Relationship between cervical sagittal alignment and health-related quality of life in adolescent idiopathic scoliosis. Eur Spine J. 2016;25:3114-9.

40. Ames CP, Blondel B, Scheer JK, Schwab FJ, Le Huec JC, Massicotte EM, Patel AA, Traynelis VC, Kim HJ, Shaffrey Cl, et al. Cervical radiographical alignment: comprehensive assessment techniques and potential importance in cervical myelopathy. Spine. 2013;38:S149-60.

41. Vialle R, Levassor N, Rillardon L, Templier A, Skalli W, Guigui P. Radiographic analysis of the sagittal alignment and balance of the spine in asymptomatic subjects. J Bone Joint Surg Am. 2005;87:260-7.

42. Schwab FJ, Blondel B, Bess S, Hostin R, Shaffrey Cl, Smith JS, Boachie-Adjei O, Burton DC, Akbarnia BA, Mundis GM, et al. Radiographical spinopelvic parameters and disability in the setting of adult spinal deformity: a prospective multicenter analysis. Spine. 2013;38:E803-12.

43. Roussouly P, Gollogly S, Berthonnaud E, Dimnet J. Classification of the normal variation in the sagittal alignment of the human lumbar spine and pelvis in the standing position. Spine. 2005;30:346-53.

44. Jackson RP, McManus AC. Radiographic analysis of sagittal plane alignment and balance in standing volunteers and patients with low back pain matched for age, sex, and size. A prospective controlled clinical study. Spine. 1994;19:1611-8.

45. Lafage V, Schwab F, Patel A, Hawkinson N, Farcy JP. Pelvic tilt and truncal inclination: two key radiographic parameters in the setting of adults with spinal deformity. Spine. 2009;34:E599-606.

46. Protopsaltis T, Schwab F, Bronsard N, Smith JS, Klineberg E, Mundis G, Ryan DJ, Hostin R, Hart R, Burton D, et al. TheT1 pelvic angle, a novel radiographic measure of global sagittal deformity, accounts for both spinal inclination and pelvic tilt and correlates with health-related quality of life. J Bone Joint Surg Am. 2014:96:1631-40

47. Lee SH, Kim KT, Seo EM, Suk KS, Kwack YH, Son ES. The influence of thoracic inlet alignment on the craniocervical sagittal balance in asymptomatic adults. J Spinal Disord Tech. 2012;25:E41-7.

48. Lafage R, Challier V, Liabaud B, Vira S, Ferrero E, Diebo BG, Liu S, Vital JM, Mazda K, Protopsaltis TS, et al. Natural head posture in the setting of sagittal spinal deformity: validation of Chin-brow vertical angle, slope of line of sight, and McGregor's slope with health-related quality of life. Neurosurgery. 2016;79:108-15.

Ready to submit your research? Choose BMC and benefit from:

- fast, convenient online submission

- thorough peer review by experienced researchers in your field

- rapid publication on acceptance

- support for research data, including large and complex data types

- gold Open Access which fosters wider collaboration and increased citations

- maximum visibility for your research: over $100 \mathrm{M}$ website views per year

At $\mathrm{BMC}$, research is always in progress.

Learn more biomedcentral.com/submissions 